\title{
From a Triangular to a Pentagonal Model in Teachers Training Practicum
}

\author{
Edni Naifeld ${ }^{1} \&$ Yonit Nissim ${ }^{1}$ \\ ${ }^{1}$ Faculty of Education, Ohalo College, Katzrin, Israel \\ Correspondence: Yonit Nissim, Faculty of Education, Ohalo College, Katzrin, Israel. E-mail: yonitn@ohalo.ac.il
}

Received: July 7, 2020 Accepted: August 10, 2020 Online Published: August 17, 2020

doi:10.5539/jel.v9n5p89 URL: https://doi.org/10.5539/jel.v9n5p89

\begin{abstract}
Teacher-training has been developed through a complex weave of processes, models and theories, founded on experiences in educational settings. In 2015, the Academia Class program was added to teacher-training programs in Israeli academic colleges and universities and added new ways of thinking about student teachers' practical experience. The program was widely implemented and became the flagship for teacher-training processes in Israel. As part of the program, student teachers and education students in their third year of studies participate in broad practical training for 12-16 weekly hours (for a year) in various educational institutions. Some of the changes engendered meaningful insights and processes that helped to reshape training processes. This article is derived from qualitative research that was involved in forming new models in teacher training, and offered an improved and enhanced approach to clinical practicum.

Traditional pedagogic instruction is based on a "triangular instruction model" (student/teacher trainer/pedagogic instructor). The present study aims to expand this model by offering a new "pentagonal model." The pentagonal model incorporates the following roles: student/coach-teacher/pedagogic instructor/coordinator teacher/academic instructor. The proposed model creates an ecosystem based on teacher-training processes and reinforces reciprocal connections, and different figures in new roles. It aims to connect the loose ends among the various participants involved in the practicum process in a more comprehensive and holistic manner. The practicum is performed in real time in the education field, in a clinical manner and is very meaningful for the future teachers' work.

Research method: Qualitative action research, documenting the expansion of the practical experience model at Ohalo College in northern Isrel. The proposed model is based on the authors' experience from the past five years, as recorded in protocols, and work papers, as well as many meetings and discussions. It is important to emphasize that the model was tested and gradually improved, becoming refined through a dynamic process using feedback between the college and its students, and between the teachers and the instructors and pedagogic instructors. Participants included more than 500 students, 500 school and kindergarten teachers, and 40 pedagogic instructors, instructors, lecturers and others in relevant roles.

The theoretical framework for the model relies on the concept of Pedagogic Content Knowledge (PCK), which emphasizes and reinforces pedagogic activity in the context of disciplinary knowledge content. In our opinion, the implementation of the model according to the approach described below creates a stable foundation for the student teacher practicum, in a manner appropriate given the current winds of change. The model should be applied in conjunction with essential changes in structural and behavioral policies necessitated by the Academia Class program.
\end{abstract}

Keywords: PCK, teacher-training, teaching practicum, triangle model

\section{Theoretical Background}

\subsection{Pedagogy, Content, and Practical Experience in the Teaching Practicum}

Teacher-training programs are founded on the approach of learning through practical experience. According to Kolb (1986), all learning is based on a repeating, four-stage cycle. Initially, there should be "concrete, practical experience" that affords a significant emotional experience. The second stage involves "reflective observation", which entails personal reflection and group mirroring concerning the experience, during which insights emerge about the practical experience. In the third stage, the reflections are used to analyze the experience and form 
conclusions about the practice, which engenders the beginning of abstract conceptualization. In the last stage of "active experimentation", the learner tries to understand their lived experience. Thus, the training of all student teachers includes the practical experience of teaching pupils in educational settings as well as critical thinking, conceptualization about, and implementation of what they learn (Zilberstein, Pnaievski, \& Guz, 2005; Zuzovsky \& Donitsa-Schmidt, 2017). Theoretical knowledge studied in college courses is translated into practice in the field, and this helps to shape teachers with strong academic abilities and subject-specific knowledge who are able to use practical tools to cope with the challenges in the field (Ran, 2018; Ronfeldt \& Reining, 2012). Several studies indicate that maximum exposure to teaching practice, closely monitored by a teacher trainer, increases the students' readiness for their role as a teacher (Maskit \& Mevurach, 2013), and students report that practical experience is a very meaningful component of their studies (Brandburg \& Ryan, 2001; Brett, 2006; Walkington, 2005).

Many studies indicate the importance of shaping teachers' professional identity through the combination of pedagogic knowledge with the teaching skills that the student acquires during their practicum (Jacob, Hill, \& Corey, 2017; Taylor \& Cranton, 2012). In contrast, the reality of fieldwork highlights the challenges and gaps in the students' performance when transferring their theoretical knowledge, gained in their studies, to the practical work of a teacher in the field (Appleton, 2003). These studies indicate that there is room to strengthen the connections between practical work and theoretical learning, in order to attain the goal of creating metacognitive processes and contexts at all stages of teacher training and practical experience (Wæge \& Haugaløkken, 2013). This approach follows the constructivist construction noted by Shulman (1987) in his description of the connections that form Pedagogic Content Knowledge (PCK).

\subsection{Teacher-Training in Israel}

In Israel, responsibility for teacher training is divided between two bodies: The Ministry of Education and the Council for Higher Education. Teacher-training programs are based on two different learning tracks: (1) the "parallel" track, in which students acquire knowledge of a particular discipline in parallel with their pedagogic studies. This takes a period of 3-4 years as the students earn their bachelor's degree and teacher's certificate; (2) the "cumulative" track, in which the student acquires a bachelor's degree in a particular discipline and only then begins their teacher training. The training period for teaching is relatively short, as is the practicum in teaching (Zuzovsky \& Donitsa-Schmidt, 2017).

\subsubsection{Models of Teaching Practicum}

There are currently three types of models for teaching practicum in Israel, as outlined below:

In the traditional model, the practicum relies on three roles: the student teacher, the pedagogic instructor, and the teacher trainer. This model does not see the school, the functionaries working in the school, or collaboration of any sort as a significant resource for the training process (Zilberstein, Guz, \& Pnaievsky, 2005). The student teacher experiments with a marginal model - that is, most of the learning consists of mimicking the model presented to him of her by the teacher trainer, rather than being based on their own actual teaching experiences (Lahav, 2010). The main assumption of this model is that learning takes place in academic institutions, with practical experience taking place in the school or kindergarten (Zilberstein, Pnaivsky, \& Guz, 2005).

The second type of model that is used involves peer models and co-teaching for the student teacher's professional development. One example of this is the model of Professional Development in School (PDS). This type of model takes a broader, deeper view of practical training. Firstly, practical experience does not only involve "practicing" the material studied in theoretical courses. These collaborative models see the practicum itself as an opportunity for learning, for constructing and internalizing knowledge. In this approach, practical-reflective work is itself considered learning (Zilberstein, Pnaievsky, \& Guz, 2005). This model focuses on organizational aspects such as the encompassing "umbrella" and pedagogical aspects such as the "essence": The encompassing umbrella consists of long-term communication with selected schools, with a commitment to the overall process and involving large groups of student teachers and many hours of practicum. The "essence" refers to wide-ranging work with the entire school, including individuals in different roles. Thus, student teachers are exposed to different levels of the teacher's work and participate in learner communities (Ariav, 2014; Ariav \& Smith, 2006; Maskit \& Mevurach, 2013).

The third type of model that is used are clinical models, such as the "Academia Class" and "Academia Colleague" models. These are founded on a perception of teaching as a technically complex profession that requires the use of dynamic knowledge. Its development was inspired by the medical model, which relies on comprehensive clinical practical experience and emphasizes technical skills, the application of theories, concepts, principles, and interpretations, as well as analysis and action. This experience takes place in parallel with the acquisition of 
academic theory, which shifts the focus of the training to the school (Ariav, 2014; Kriewaldt \& Turnidge, 2018). Several studies show that this collaborative model has advantages over other training methods in terms of the prevention of student teacher dropout and the achievements of pupils during the first year of novice teachers' work. It was also found that the student teacher's sense of self-efficacy improved when they learned and taught pupils in schools as part of their teacher training according to the collegial model (Allen, Ambrosetti, \& Turner, 2013; Hoy \& Spero, 2005; Naifeld \& Nissim, 2019; Latham \& Vogt, 2007; Ridley, Hurwitz, Hackett, \& Miller, 2005).

\subsection{The Academia Class Program for Optimal Practicum Training}

In recent years, on the initiative of the Ministry of Education and with the support of teacher-training institutions, various programs and initiatives have been implemented to improve teacher-training processes, the most significant of which is the Academia Class program. The program, which was initially designated as experimental, was widely implemented in 2015 and quickly became the flagship for teacher-training processes in Israel. As part of the program, student teachers and education students in their third year of studies participate in broad practical training for 12-16 hours per year in various educational institutions. The students are guided by a teacher trainer from the school or kindergarten to which they are assigned, with whom they teach as co-teachers, in a collaborative model. The students take part in all educational activities and provide additional teaching resources. They are gradually integrated into activities of observation, assistance, one-on-one teaching, and teaching a full class alongside the teacher trainer. Their presence reduces the teacher-pupil ratio in the classroom and enhances meaningful learning. The Academia Class program has several defined goals:

(1) Reinforcement of the partnership between colleges/universities, schools and kindergartens, and the Ministry of Education's regional offices

(2) Improvement of student teachers' training

(3) Promotion of the professional expertise of experienced school and kindergarten teachers who participate in the training of student teachers

(4) Advancement of meaningful learning in schools (Ministry of Education Thinktank, 2014).

Studies that investigated the Academia Class program from various aspects and sought to assess its contribution to teacher-training processes have found that the program's graduates had a strong sense of self-efficacy and readiness for the teaching role and had a better chance of successfully integrating into the teaching profession (Eran \& Zaretski, 2017; Macdusie, 2018). Teachers and students who participated in the program expressed their satisfaction and believed that it contributed to everyone involved: teachers, student teachers, and pupils (Arnon \& Presco, 2018; Ratner \& Shmuel, 2017). Ronen, Daniel-Saad and Holtzbart (2018) found significant differences between the knowledge (relating to subject matter, pupils, the teaching process, and parents) that students in the Academia Class program acquired in comparison to knowledge acquired in the traditional teacher-training program. Neifeld and Nissim (2019) found that the program made a significant contribution to the acquisition of teaching practices, co-teaching skills, and interpersonal interactions between teacher and pupils.

\subsection{The Instruction Triangle - the Traditional Model}

Research literature conceptualizes student teachers' practical experience using the "instruction triangle". The trio of partners that participates in this experience is also referred to by Murrell (2001) as the "clinical triad". The triangular model includes the student teacher; the pedagogic instructor, who is a representative of the training institute and is responsible for the student's professional training during their practicum in the training-classroom; and the teacher trainer who is present in the classroom where the student practices teaching. Emphasis is given to reciprocity and cooperation in the relations between the three partners (Zilberstein, Pnaievsky, \& Guz, 2005). 


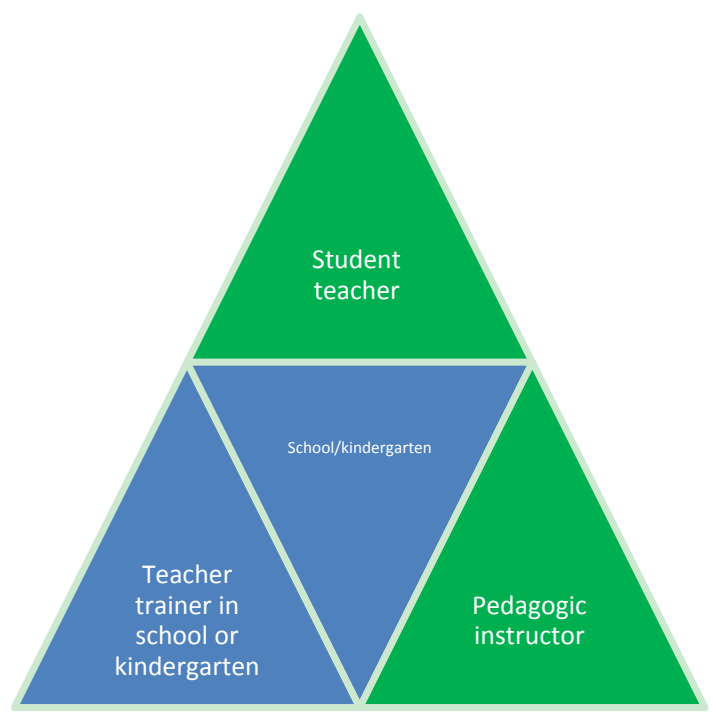

Figure 1. Graphical illustration for the instruction triangle - the traditional model

Note. Green background - responsibility of the college; Blue background - responsibility of the school or kindergarten.

\subsubsection{The Student Teacher in the Practicum}

Practical experience in teaching is a fundamental element of teacher-training. The field practicum is the space in which the meeting of three significant dualities of the teaching act take place: the dualities of discipline and education, theory and practice, in the education field (Hamer-Bodenaro, 2014).

In this context, the student tries to translate theory into action and to indirectly become more familiar with the school as a workplace and with other teachers. Practical experience enables the student to exercise planning and teaching and to critically observe the application of theories and systems (Dvir, 2005; Eyal, 2006; Lam, 2000; Zuzovsky, 1991). This practical experience varies according to the level of involvement by the student teacher in classroom teaching. In certain cases, the student passively learns by observing the teacher trainer as they teach, only later gradually beginning to take on an active teaching role. In other cases, student teachers find themselves managing a lesson and classroom without any co-teachers, assistants, supervision, or instruction from a teacher trainer. The correct balance between the opportunities for different types of experiences and the provision of supervision and control enhances the student teacher's professional development (Bacharach, Heck, \& Dahlberg, 2010).

The experience of teaching activates a gradual process of change, enabling the student teacher to develop reflective abilities and to identify their strengths and weaknesses. These abilities provide a basis for the continuation of the learning process throughout their career (Lai, 2005; Rajuan, Beijaard, \& Verloop, 2008). Additionally, the observation and experience of teaching contributes significantly to teachers' future self-realization (Clark \& Newberry, 2019).

\subsubsection{The Teacher Trainer}

The teacher trainer is usually a teacher with appropriate characteristics and teaching abilities who can provide a desirable professional model for the student teacher (McCormack \& West, 2006; Ziv, Zilberstein, \& Tamir, 1992). The teacher trainer's role covers a broad range of functions, including that of professional teacher, critic, and evaluator as well as guide, companion, and source of support (Bray \& Nettelton, 2006; Busher, Gündüz, Cakmak, \& Lawson, 2015; Sundli, 2007). The teacher trainer's role focuses on three areas:

(a) Development of teaching skills: the teacher trainer constitutes a model for educational and pedagogic activities and offers the student teacher a concrete experience of the teaching profession. The teacher trainer enables the student teacher to experience different types of teaching experiences, analyze them, conduct reflective conversations on those experiences, and analyze various scenarios that arise (Fairbanks, Freedman, \& Kahn, 2000; Lai, 2005; Le Maistre, Boudreau, \& Pare, 2006).

(b) Development of ecological observation: the teacher trainer explains the curricula and aspects relating to evaluation, classroom climate, and working with parents. He or she also arranges meetings for the student teacher with the school as an organizational unit, allowing the student teacher to experience relationships with 
those who hold different roles in the school (Feiman-Nemser, 2003; Lai, 2005).

(c) Support and guidance: the teacher trainer serves as personal instructor and mentor for the student teacher throughout the practicum (Carr, Hermann, \& Harris, 2005). It was found that care and support for the student teacher is a central component for the success of the practicum (Boreen, Johnson, Niday, \& Potts, 2003). In parallel to this role, the teacher trainer performs their teaching role, as a companion to the student teacher (Jaspers, Prins, Meijer, \& Wubbels, 2018).

Teacher trainers also develop and grow through their experience in this role. It was found that, thanks to their guidance of the student teachers, teacher trainers become more involved in the implementation of educational initiatives and thereby delve more deeply into content, pedagogy, and evaluation. To perform their role optimally, they need the cooperation of the college; this involves maintaining uniform professional language and terminology in conjunction with pedagogical instructors as well as complying with organizational arrangements such as shared methodical planning and problem-solving (Ziv, Zilberstein, \& Tamir, 1992; Zidan \& Aliyan, 2013).

The introduction of the Academia Class program included an aspiration that the role of the teacher trainer would shift from that of teaching pupils to one of mentoring student teachers as co-teachers, including shared planning, co-teaching in the classroom, ongoing shared activity and dialogical feedback, ongoing learning, and investigation of practice in a shared professional community. The Academia Class program emphasized the formation of reciprocal relationships founded in respect and care. This experience is intended to influence the professional development of the teacher trainer (Guise, Habib, Thiessen, \& Robbins, 2017).

\subsubsection{The Pedagogic Instructor}

The pedagogic instructor is an experienced teacher who serves as the "guide" for the student as they undergo the developmental process of becoming a teacher (Ran, 2017). This person connects and mediates between the academic-theoretical realm of theories and college courses and the issues that arise in the professional field (Yogev \& Zuzovski, 2011; Milat, 1999). The substance of pedagogic instruction is the interpersonal meeting between the instructor and the mentee, which relies on continual and developing bi-directional discussion (Katz, 2011).

In most teacher-training programs, the training institution's teacher-educators guide the student teachers through observation sessions and provide feedback based on these observations. This guidance is an integral part of the practicum experience performed during the teacher's academic training. The attempt to find a decisive and unambiguous definition for a pedagogic instructor is challenging, because of the ambiguity of this term with respect to the distinct features of the role and the fact that the instructor operates in a sort of third space that bridges the college/university and the school or kindergarten in which the practicum take place. Furthermore, there is no particular training nor defined prerequisites to become a pedagogic instructor (Ran, 2017).

The pedagogic instructor fulfils four main functions:

(a) Support for the mentee's personal development process. The pedagogic instructor guides the personal growth process, providing emotional support and motivation. The relationship between the instructor and the mentee is unique and personal (Katz, 2011; Emanuel, 2005).

(b) Promoting professional teaching abilities and compliance with desirable norms and standards (Emanuel, 2005). Soslau (2012) suggests different ways to achieve this goal: (1) Telling, in which the instructor makes suggestions, guides, and presents ideas for improvement; (2) Coaching, in which the instructor intervenes in the student teacher's reflections and enables them to formulate, values, and assumptions and to test alternative scenarios for events; (3) Guidance, in which the instructor focuses on the "why" rather than "how" or "what" of teaching, examining the student teacher's plans and intentions; (4) Research, which involves collaborative investigation of possible reasons and solutions for different scenarios. Drawing from reflections on classroom activities, the instructor provides relevant contexts for reference, and together with the student teacher, considers situations that are a result of their collaborative work.

(c) Promoting the functions of evaluation and feedback. The pedagogic instructor observes the student teacher at work and reflects on the teaching quality together with the student teacher and teacher trainer. This process is part of the quality control evaluation conducted in parallel for the student teachers and provides them with a tool that can improve their teaching skills and serve as part of their life-long professional learning (Lam, 2000; Milat, 1999; Emanuel, 2005).

(d) Forming and maintaining a connection with the training institutions the teacher trainer, and other individuals in the college. The connection with the school as an organization and the reciprocal relations with the college 
play a more important role in collaborative models of instruction such as PDS and Academia Class than in traditional models (Milat, 2005). With the introduction of the Academia Class program in Israel, there was an expectation that the role of the pedagogic instructor would be expanded. The expanded role would include student-focused pedagogic instruction as well as leading professional development processes in the schools and kindergartens in which the practicums take place in order to foster joint learning in a professional community comprising the student teachers, school/kindergarten teachers, and college staff. This professional development processes should be accompanied by research that will influence the implementation of training practices in the field, including changes and improvements for guidance and training (Grossman, Hammerness, \& McDonald, 2009; Loughran, 2014).

\section{The Research}

\subsection{Research Method}

This article relies on qualitative-theoretical research. The qualitative approach was chosen because of its ability to systematically collect and analyze data, to construct a holistic picture of the studied phenomenon, and to clarify its substance and meaning from the viewpoint of members of the studied community in their natural environment (Sabar Ben-Yehoshua, 2016; Shkedi, 2003). This type of research also includes characteristics of the case study by focusing on an object, person, system, or process that the research wishes to understand in depth. Furthermore, the research adopted an action research approach backed by grounded theory, which relies on a constructivist approach. This approach advocates different interpretations for processes of change through the construction of experiential memory and clear documentation, and helps to describe and explain multifaceted and complex phenomena rather than discover a new reality (Sabar Ben-Yehoshua, 2016). In this research approach, the researchers, beyond their role as the scholars behind the study, are involved as participants who experience the described processes, their implementation in practice, their investigation and improvement, and the construction of practical models.

We focused our interest on the intervention processes as well as the improvement of models of teachers' practical experience. Our aim was to enable the development of a theoretical approach that could be translated into practical, applicable knowledge for those engaged in the educational aspects of student teachers' practicum.

\subsection{The Proposed Model: From Triangular to Pentagonal Instruction}

With the expansion of the college's activities in the Academia Class program, several concrete challenges arose concerning the pedagogic instructors, the student teachers' needs, the relationship with the schools/kindergartens, and the bureaucratic management of the program. At the same time, as we accumulated experiences and familiarity with the program and its needs, we became aware of the challenges facing us and altered the pedagogic instruction as appropriate for the new model. The changes were performed gradually, based on results from surveys and research.

The modifications were driven by the desire to create processes of change in traditional and conventional teacher-training paradigms in order to adapt them to current reality. However, the constructivist building needed to connect more deeply to and cement the connections between the theoretical management of disciplinary education and the instructional and educational methods applied in the classroom. Such training reduces gaps between theoretical approaches delivered in college lectures and the practical experience student teachers undertake in the field during their training. The approach to change that echoed continually throughout the process was based on the PCK approach (Shulman, 1987), which was later expanded on by including technology-assisted teaching to become the Technological Pedagogical Content Knowledge (TPACK) model (Koehler \& Mishra, 2006).

In our view, motivation to change and improve the training paradigm created a new space within each of the practicum sites, which we have called a "third space." The third space is neither an academic/theoretical space nor a practical space of fieldwork, but rather a point of meeting and bonding between the two (thus the link in the name "Academia-Classroom"). In this third space, there is continual learning shared by teachers, pupils, student teachers, and academics. This space is intended as a place to strengthen the connection between teaching and teacher-training, and to improve the design of teaching methods and promote research and practical knowledge in this area (Furlong, 2011).

\subsection{The Model-Building Process}

\subsubsection{The First Year}

In its first stage as a pilot study, a unique practicum program was offered to students with strong capabilities, in exchange for a participation scholarship. The pilot group participated in 16 practicum hours for three days a 
week in schools/kindergartens. This differed from the regular practicum, which took place one day a week.

A network of valuable collaborations was constructed between the college and the Ministry of Education's schools, kindergartens, and teacher development centers. Additionally, other new roles were included in the model: an academic coordinator, whose function was to help implement the program; education lecturers who conducted the training for the student teachers; and a school coordinator who coordinated the program in the schools and kindergartens. The title of "teacher trainer" was changed to "coach-teacher," and these individuals were given greater responsibility for the training of the student teachers.

Even in the first year, several challenges arose in the program that required attention:

(a) Due to the size of the geographical area covered by the practicum, the pedagogic instructors met with the student teachers very infrequently. Moreover, the increased number of hours and days for the practicum and the shifting of responsibilities to the coach-teacher increased the importance of the coach-teacher over the pedagogic instructor. These coach-teachers were not always able to model excellent teaching due to challenges in their schools such as the large number of students.

(b) The implementation of innovative pedagogy was found to be challenging. Despite serious efforts by the college to train teachers to be better suited for the challenges of the twenty-first century, the young student teachers chose to imitate the coach-teachers, many of whom employed traditional approaches. The student teachers found it difficult to implement the principles of innovative pedagogy that they had studied in college, and they instead implemented the traditional teaching principles practiced in the schools.

(c) Training the coach-teachers: At the beginning of the program, college lecturers, experienced in professional teacher development, were enlisted to guide the coach-teachers. However, in the follow-up after the training, there seemed to be a gap between what occurred in the schools/kindergartens, the human interactions between the coach-teacher and student teacher, pedagogic issues with the content of the training, and the ability of the pedagogic instructor to understand and help the coach-teachers.

Despite these challenges, the initial pilot demonstrated strong development of the student teachers' skills and meaningful connections were formed between the schools/kindergartens and the college. At the end of the pilot year, several of the program's graduates were employed by the schools in which they had conducted their practicum year.

\subsubsection{The Second Year}

During the next year, the learning structure for all of the student teachers was changed, and all third-year students in the regular track at the teacher's college were enrolled in the Academia Class experimental program. The training of school coach-teachers was separated from that of kindergarten coach-teacher. The pedagogic instructors for early childhood provided special training for the kindergarten coach-teachers. This approach proved to be especially effective. The pedagogic instructors, who were acquainted with the student teachers from the college, guided them in their practicum working with kindergarten teachers and helped foster the connection with the training program. At the end of the second year, we determined that three additional challenges required attention:

(a) The absence of pedagogic instruction in the beginning of the school year: While schools and kindergartens in Israel begin on September 1st, the college semester begins at the end of October. Since the pedagogic instructors are employed by the colleges, they did not begin serving in their role until the end of October. As part of the Academic Class experimental program, student teachers underwent several days of preparation at the end of August to prepare for the school year. However, there was a gap of approximately two months in which the student teachers did not receive pedagogic guidance or direction. As a result, the student teachers sometimes developed unsuitable practices and teaching habits during this period.

(b) The difficulty of providing immediate, individual, focused responses to student teachers: with an increase in the number of student teachers and participating schools, the number of issues and conflicts also increased, indicating a growing need for the presence of a college representative in the schools.

(c) Defining the school coordinator's role: according to the program's instructions, a coordinating teacher at each school was appointed and compensated. At first, the position's responsibilities were left open to interpretation by the coordinator. However, we determined that it was necessary to define the coordinator's work and to use this resource in an intelligent manner to improve the college-school partnership.

To reinforce the pedagogic instructors' influence on the student teacher, they were offered additional work hours and their areas of responsibility were broadened beyond discipline-specific instruction. The pedagogic 
instructors were asked to manage the procedures for working with the schools, to advance joint projects, and to lead the training for coach-teachers. This approach proved unsuccessful for personal and organizational reasons.

\subsubsection{The Third and Fourth Years}

In the third year, the role of "academic instructor" began to crystallize, with the addition of two instructors who reinforced the use of innovative pedagogy in the schools that had adopted the Academia Class program. Student teachers were provided with guidance and support to encourage them to implement a variety of innovative teaching methods.

The fourth year began with four instructors who guided the student teachers in the mornings and who also performed the schools' teacher-training. In parallel, the early childhood instructors continued to guide the kindergarten teachers' training.

\subsubsection{Fifth Year}

During this year, as a result of experience and conceptual refinement, the role of the academic instructor was further reinforced, the role of school coordinator was clarified, and a "pentagonal model" was constructed as an optimal response to incorporate collaboration and reciprocal relationships into student teacher training.

\subsection{The Pentagonal Model}

This model was created to provide an optimal approach to teacher-training, involving a network of collaborations and reciprocal relationships developed over the course of the five-year process described above. The model relies on an ecosystem that creates links between traditional models and approaches (PCK) and an overarching innovative support system in a technology-assisted space (TPACK). A multi-dimensional model was thus formed on the basis of this web of connections. The model has been given the name "the pentagonal model."
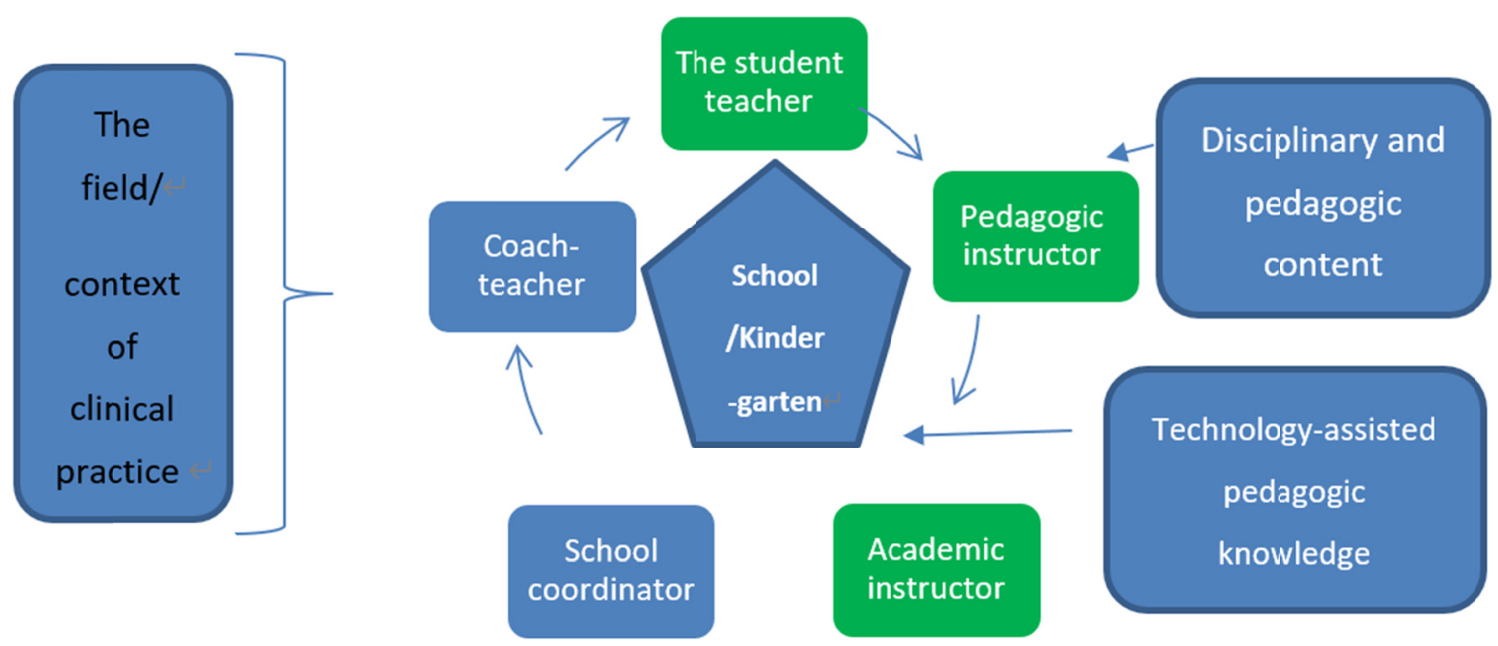

Figure 2. The Pentagonal Model

Note. Areas with green background—Under the college's responsibility; Areas with blue background—Under the school's responsibility.

\subsubsection{The Network of Collaborative Relations}

The proposed model is composed of five key individuals who each represent a segment of the pentagonal model for the clinical practicum. In fact, the pentagonal model creates an ecosystem that provides a broad overarching umbrella for various challenges that arose while developing the Academia Class program, and particularly from the desire to create an optimal practicum in for student teachers.

The number of individuals involved in the model required the use of managerial strategies and organized work programs as well as the preparation of documents, role files for task setting, and clear role definitions. Achieving this optimal model required an approach that demonstrated sensitivity, flexibility, and transparency. This was not an easy path; it involved a high degree of complexity at the interfaces and between the different entities involved. In this interweaving of relationships, there were tensions and difficulties that arose, requiring the facilitation of 
solutions. Below, we describe some of the complexities that arose from the use of the pentagonal model.

(a) Interaction between the pedagogic instructor and the academic instructor. Introducing an additional person from the college into the relationship between the student teacher and the pedagogic instructor initially prompted debate, suspicion, and murmured remarks, including questions such as: who is responsible for the student? Who will evaluate the student? To whom will the student turn with difficulties? What about disciplinary guidance? Etc.

(b) Bureaucratic issues of follow-up and control. As a result of the experiment, clear role definitions were composed, and the areas of responsibility were demarcated for each of the individuals. Thus, for example, the pedagogic instructors ceased to manage the follow-up of student teachers' behavior during the practicum, assuming that this would be undertaken by the coach-teacher and the coordinator. Consequently, gaps appeared, and it was decided to restore the traditional follow-up by the pedagogic instructor along with the coordinator.

(c) The dilemma of affiliation: Who does this student teacher "belong" to? After incidents were resolved by the instructor and clarified in retrospect with the pedagogic instructor and vice-versa, it was decided to stipulate that these individuals would serve as partners and be required to notify and consult with the other on all relevant issues.

(d) Clashes arising from the PCK background and issues concerning the system as opposed to disciplinary considerations. Tensions arose about the assignment of the student teachers to the coach-teachers. The choice of the optimal professional teacher was made by the pedagogic instructor. The school coordinator was asked to assign the student teachers in a particular school and to use the existing reservoir of teachers in the school. Often the pedagogic instructor did not think the chosen teachers were suitable because of their work methods or because of the age group they taught.

Following these incidents, steps were taken to improve the situation: each pedagogic instructor composed guidelines for disciplinary practical experience, which improved the coach-teacher selection process and implementation of the practicum. It was also decided that the pedagogic instructors would participate in the assignment meeting and would express their opinion concerning the selected teachers.

(e) Teamwork. It took some time until the pedagogic instructors trusted the role of the academic instructor and understood the importance and necessity of working in close cooperation with the pedagogic instructors. Openness and flexibility played an important role in enabling the participants to work together in support of the student teachers.

(f) Reinforcing the relationship between the academic instructor (from the college) and the school coordinator. On one hand, the school coordinators are the representatives of the student teachers in the program; they must oversee the entire process and guide the training for the student teachers. On the other hand, the academic instructor in this model becomes part of the Academia Class staff in the school. They maintain contact with the individuals in different roles and are involved in school procedures. Both the coordinator and the pedagogic instructor need to integrate into the parallel system - to get to know it and to support it. The ability to see beyond traditional roles and beyond loyalty to their habitual workplace is very important, for the sake of effective communication and optimal training.

\subsubsection{Definition of Role Holders in the Pentagonal Model}

\subsubsection{The Academic Instructor: A New Role in the Training Space}

The pedagogic instructor is a professional who has undergone academic training in education and completed studies for a teaching certificate. They have experience in working in schools and experience in mentoring student teachers. They are responsible for all the student teachers, irrespective of their discipline, in several schools. The academic instructor has various functions:

(a) Accessibility to the student teachers and development of personal relationships: the academic instructor works in the school at least once every two weeks. They are significant figures who accompany the student teachers throughout the practicum. They serve as guides, trainers, and mentors. The academic instructor does not replace or contradict the guidance of the pedagogic instructor, but accompanies and complements their work.

(b) Assignments: the instructor prepares the assignments together with the school for the following practicum year, while maintaining contact with discipline-specific pedagogic instructors and student teachers. A successful assignment requires a delicate interplay of considerations, taking a variety of factors into account including compliance with the necessary regulations and requirements.

(c) Follow-up on the student teacher's integration and appropriate activity in the practicum: the academic 
instructor, who frequently visits the school, monitors the student teacher's regular attendance through reports from the coordinator (as noted below), including the student teacher's performance, and provides an immediate response to challenges that arise. Any special difficulties or successes of note are discussed with the discipline-specific pedagogic instructor.

(d) Reinforcement and enabling of innovative pedagogy: the academic instructor meets with the student teachers, observes some of their lessons, and guides them to vary their teaching methods in line with twenty-first century needs. This occurs in parallel with the pedagogic instructor's guidance.

(e) Training the coach-teachers: the academic instructor also serves as mentor for training the coach-teachers in the program. The training course includes subject matter relating to co-teaching and to the development of mentoring and feedback skills, and involves analyzing situations arising from daily life at the school, where they also meet the academic instructor.

(f) Co-teaching: one of the goals of the Academia Class program is to increase the extent of the student teacher's involvement in the practicum setting until they are working together with the coach-teacher as a second teacher in the classroom. The academic instructor teaches the student teachers the principles of co-teaching and guides this teaching in the classrooms.

(g) Follow-up and supervision of the program's policies: the academic instructor notes whether the policies and regulations of the Academia Class program are being followed. They make sure that a weekly meeting takes place between the coach-teacher and the student teacher, that co-teaching is taking place, that lessons are taught according to the instructions of the pedagogic instructor, and that there is involvement in activities beyond the learning program.

\subsubsection{The Disciplinary Pedagogic Instructor}

The pedagogic instructor in the Academia Class program is responsible for the guidance of professional teaching, in a weekly lesson. The instructor follows the student teacher's weekly progression as captured by follow-up worksheets, reports, blogs, timetables etc. Additionally, the instructor observes the student teacher as they teach lessons in the school, and communicates with both the student teacher and the coach-teacher.

The pedagogic instructor participates in preparing the assignment of student teachers to the various coach-teachers. They establish the criteria for choosing good, professional teachers and participate in choosing them at the school, as well as outline the instructions for the specific practicum. Difficulties or special problems that arise in the practicum are addressed either by the pedagogic instructor or the academic instructor depending on their availability and/or the topic at hand. In any case, communication between the pedagogic and academic instructors is required.

\subsubsection{The Coach-Teacher}

In the Academia Class program, the coach-teacher is a skilled and experienced teacher of the disciplinary specialization of the student teacher. The teacher accompanies the student from the start, when preparing for the school year, until the year's end. The coach-teacher serves as the mentor for the student teacher, providing a personal model of optimal teaching, helping the student become familiar with long-term processes and educational curriculum in teaching, co-teaching with the student teacher, helping them prepare and conduct lessons, and then analyzing them and to learn from the experience. The coach-teacher introduces the student teacher to a range of educational situations in the classroom and enables them to experience the teacher's work activities outside of lessons: pupil evaluations, meetings with parents, staff meetings, etc.

One hour each week is reserved for meetings between the coach-teacher and student teacher. This hour provides time and space for reflection, learning, and planning. The coach-teacher maintains contact with the disciplinary pedagogic instructor, receiving specific instructions from the instructor for the disciplinary practicum, works with the instructor to summarize their discussions after observations, and informs the instructor about any issues concerning the student teacher. The coach-teacher undergoes 60 hours of training, after which they participate in a yearly refresher and simulation course (8 hours annually).

\subsubsection{The School Coordinator}

The school coordinator is a teacher from the school whose function is to assimilate the Academia Class program into the school's processes. Usually the role of the coordinator is given to a teacher who holds an administrative role in the school and has a systemic view of the school, in addition to professional experience and interpersonal skills. The coordinator is responsible for the entire group of student teachers in the school and coordinates the assignment of the student teachers to suitable coach-teachers. 
The coordinator is responsible for ensuring the student teachers' involvement in activities beyond the classroom, ensuring that they meet with other school role holders and that they become acquainted with various angles of the teacher's work. The coordinator monitors the regular attendance of the student teachers in the practicum. They are also responsible for the student teachers' integration into the school's staff, welcoming and introducing them to the staff, and creating an atmosphere of acceptance and belonging for them among the staff. Together with the academic instructor, the coordinator addresses problems and handles incidents connected to the functioning of both student teachers and coach-teachers and conflicts that arise between them.

2.5 Summary of Changes in the New Model: Moving from a Triangular to a Pentagonal Model
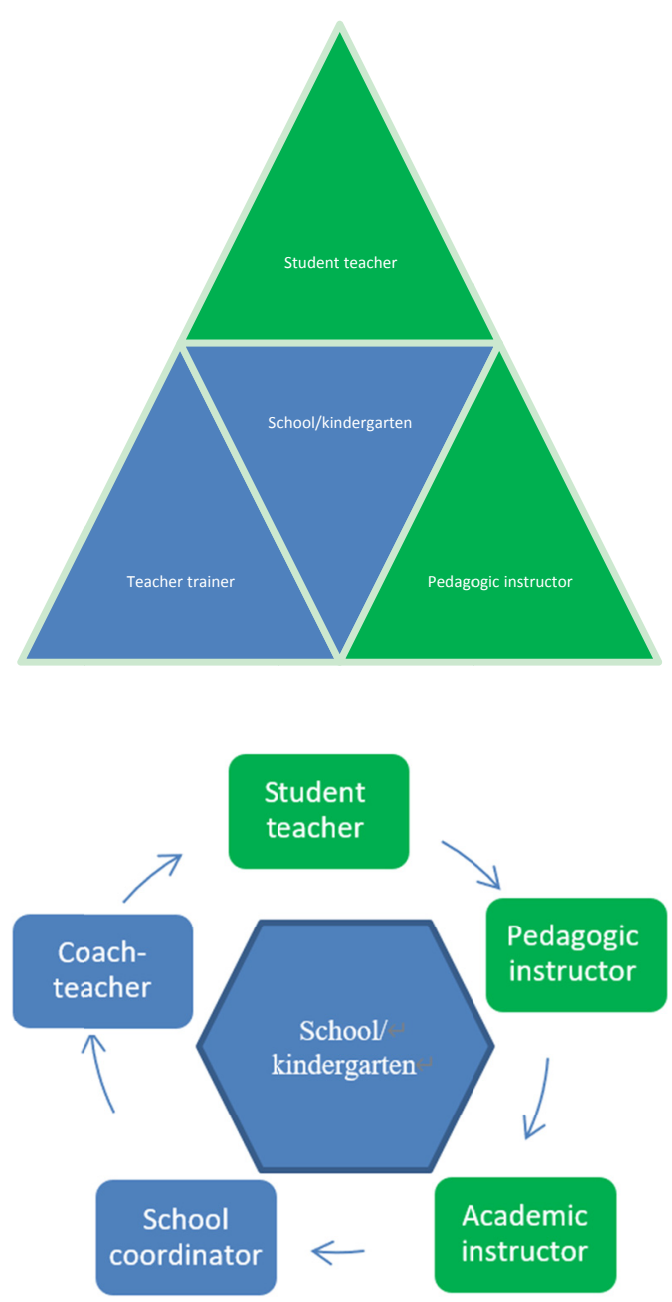

Figure 3. From a triangular model to the pentagonal model

The following table compares the triangular and pentagonal models within the Academia Class program with regard to the processes and policies involved in the student teachers' clinical practicum as part of their teacher-training processes. 
Table 1. Comparison between the triangular and pentagonal models, by role and category

\begin{tabular}{|c|c|c|}
\hline Role & Category & Triangle model \\
\hline \multirow[t]{5}{*}{ Academic instructor } & $\begin{array}{l}\text { Individual attention to and } \\
\text { availability for the student } \\
\text { teacher }\end{array}$ & $\begin{array}{l}\text { This function does not } \\
\text { exist in the triangular } \\
\text { model }\end{array}$ \\
\hline & Assignment for practicum & $\begin{array}{l}\text { By the pedagogic } \\
\text { instructor }\end{array}$ \\
\hline & $\begin{array}{l}\text { Follow-up of the student } \\
\text { teacher's integration into and } \\
\text { appropriate performance of } \\
\text { the practicum }\end{array}$ & $\begin{array}{l}\text { The pedagogic instructor } \\
\text { visits the student teacher } \\
\text { two or three times per } \\
\text { semester and maintains } \\
\text { communication with the } \\
\text { student teacher as } \\
\text { necessary }\end{array}$ \\
\hline & $\begin{array}{l}\text { Reinforcement and } \\
\text { empowerment of innovative } \\
\text { pedagogy }\end{array}$ & $\begin{array}{l}\text { Courses are provided by } \\
\text { the college, and the } \\
\text { disciplinary pedagogic } \\
\text { instructors were partially } \\
\text { involved in their } \\
\text { guidance. }\end{array}$ \\
\hline & Training the coach-teachers & $\begin{array}{l}\text { Provided by college } \\
\text { lecturers with experience } \\
\text { in teacher-training }\end{array}$ \\
\hline
\end{tabular}
pentagonal model

The academic instructor visits the school at least once every two weeks. They are important figures who accompany the student teachers, serving as guides, trainers, and instructors. The academic instructor does not replace or contradict instruction by the pedagogic instructor but aligns themselves with and complements it.

The instructor prepares the assignments for the practicum year with the school, in communication with the disciplinary pedagogic instructor and the student teacher. The success of the assignment requires consultation with stakeholders and compliance with the stipulated regulations and requirements. teacher's integration into and appropriate performance of the practicum

Reinforcement and empowerment of innovative pedagogy

Co-teaching in the Academia Class program

Follow-up and supervision of policies of the program

Pedagogic instructor

Didactic course

Assignment for practicum

The work year
The academic instructor frequently visits the school, monitoring the student teachers' attendance and performance and provides immediate response to difficulties that arises, with supervision from the coordinator (as described below). Any noteworthy difficulties or successes are addressed along with the discipline-specific pedagogic instructor.

The academic instructor meets with the student teacher, observes their lessons, and instructs them how to vary their teaching in line with $21^{\text {st }}$ century needs, in conjunction with the guidance of the disciplinary pedagogic instructor.

Also serve as the mentors for the training of the coach-teachers in the program. Their course includes dealing with co-teaching, development of mentoring skills, and feedback, as well as how to handle common situations arising in schools that are likely to be encountered by the instructor. The academic instructor teaches the student teachers the principles of co-teaching and guides this teaching in the classroom. performance and only partial guidance.

Monitors the performance of policies and regulations for the Academia Class program. Ensures that weekly meetings of the coach-teacher and student teacher take place, that student teachers attempt co-teaching, and that they teach according to the instructions of the pedagogic instructor and are involved in other activities outside the learning program.

Teaching disciplinary pedagogy workshop accompanying the practicum - processing and analyzing issues from the field Choosing schools and teachers and assigning student teachers to their practicum

In line with the academic year
Teaching disciplinary pedagogy workshop accompanying the practicum. Processing and analyzing issues from the field.

Outlining criteria for assignment and participation in determining assignments. Outlining instructions for specific practical experiences.

From the end of August, i.e. the beginning of the academic year: sending instructions to student teachers and coach-teachers concerning the work at the beginning of the year. 


\begin{tabular}{|c|c|c|c|}
\hline Role & Category & Triangle model & pentagonal model \\
\hline & $\begin{array}{l}\text { Guidance, monitoring, and } \\
\text { supervision }\end{array}$ & $\begin{array}{l}\text { Inspecting the } \\
\text { monitoring forms, } \\
\text { reports, blogs, schedules, } \\
\text { etc. Observation of } \\
\text { lessons in school and } \\
\text { participation in } \\
\text { triangular discussion: } \\
\text { student teacher, teacher } \\
\text { trainer, and disciplinary } \\
\text { pedagogic instructor. }\end{array}$ & $\begin{array}{l}\text { Inspecting the follow-up pages, reports, blogs, } \\
\text { schedules etc. Observation of lessons in school and } \\
\text { triangular discussion: student teacher and } \\
\text { coach-teacher with disciplinary pedagogic } \\
\text { instructor. }\end{array}$ \\
\hline & $\begin{array}{l}\text { Attention to } \\
\text { problems/difficulties of the } \\
\text { student teachers and } \\
\text { coach-teachers }\end{array}$ & $\begin{array}{l}\text { Individual attention to } \\
\text { every difficulty the } \\
\text { student teacher or } \\
\text { teacher trainer } \\
\text { encounters in the } \\
\text { practicum }\end{array}$ & $\begin{array}{l}\text { Addressed both by the pedagogic instructor and the } \\
\text { academic instructor, depending on their availability } \\
\text { and the type of problem. Communication between } \\
\text { the two instructors concerning the issue is required. }\end{array}$ \\
\hline \multirow[t]{2}{*}{ Student teacher } & Support and guidance & $\begin{array}{l}\text { Supported by the } \\
\text { pedagogic instructor and } \\
\text { the teacher trainer }\end{array}$ & $\begin{array}{l}\text { Guided by the pedagogic instructor, the academic } \\
\text { instructor from the college, and the coach-teacher } \\
\text { from the school. }\end{array}$ \\
\hline & $\begin{array}{l}\text { Beginning of the school year } \\
\text { at school and of the academic } \\
\text { year at the college }\end{array}$ & $\begin{array}{l}\text { Experimenting with the } \\
\text { Academia Class program } \\
\text { from the end of August } \\
\text { until the beginning of the } \\
\text { academic year without } \\
\text { the college's supervision }\end{array}$ & $\begin{array}{l}\text { From September until the beginning of the } \\
\text { academic year, the student teacher is guided by the } \\
\text { pedagogic instructor with instructions for the } \\
\text { practicum and personally supervised by the } \\
\text { academic instructor. }\end{array}$ \\
\hline \multirow[t]{2}{*}{$\begin{array}{l}\text { Teacher trainer or } \\
\text { coach-teacher }\end{array}$} & Connection with the college & $\begin{array}{l}\text { A connection exists with } \\
\text { the disciplinary } \\
\text { pedagogic instructor }\end{array}$ & $\begin{array}{l}\text { There is a connection with the disciplinary } \\
\text { pedagogic instructor and also with the academic } \\
\text { instructor. }\end{array}$ \\
\hline & $\begin{array}{l}\text { Training of trainer/coach- } \\
\text { teacher }\end{array}$ & $\begin{array}{l}\text { By college lecturer with } \\
\text { experience in } \\
\text { teacher-training }\end{array}$ & $\begin{array}{l}\text { By the academic instructor who knows the } \\
\text { coach-teachers and student teachers from their } \\
\text { work in the field }\end{array}$ \\
\hline \multirow[t]{2}{*}{ School coordinator } & Role definition & $\begin{array}{l}\text { Role involves general } \\
\text { coordination and is not } \\
\text { defined }\end{array}$ & $\begin{array}{l}\text { Responsible for integrating student teachers into } \\
\text { the school's staff, ensuring their welcome and } \\
\text { creating an atmosphere of sharing and acceptance } \\
\text { among the school staff. } \\
\text { Responsible for involving the student in activities } \\
\text { beyond the curriculum. } \\
\text { Enabling student teachers to meet those in the } \\
\text { educational institution (school q kindergarten) and } \\
\text { to understand diverse aspects of the teacher's work. } \\
\text { Monitoring the "basket of hours" outside the } \\
\text { learning program as well as the regular presence of } \\
\text { the student teachers in the practicum. }\end{array}$ \\
\hline & Connection with the college & $\begin{array}{l}\text { A connection with an } \\
\text { Academia Class } \\
\text { coordinator. }\end{array}$ & $\begin{array}{l}\text { Tight connection with the academic instructor and } \\
\text { mediated by the disciplinary pedagogic instructor. }\end{array}$ \\
\hline
\end{tabular}

\section{Summary, Conclusions, and Insights}

Teacher-training relies on a complex fabric of processes anchored in the practical training that occurs in the field of schools/kindergartens. With the introduction of the Academia Class program in 2015, we identified the need to implement significant changes in the way that colleges and universities train school and kindergarten teachers - changes to processes and policies and rethinking teachers' practicum. This reflection engendered significant insights and led to processes that have helped reshape teacher training in Israel.

The research project aimed to observe and reflect on the teacher-training process, and sought to derive a theoretical model that could be applied in teacher-training processes for student teachers' practicum experience. Based on our work, we constructed a new model that extends the traditional pedagogical training "triangular model" (student teacher/teacher trainer/pedagogic instructor) into a new "pentagonal model", which introduces a new approach aimed at creating an enhanced overarching training experience. The new model incorporates a 
new set of connections: student teacher/coach-teacher/pedagogic instructor/school coordinator/academic instructor. This is a complex human system (ecosystem) that reinforces reciprocal relations between the holders of different roles, including those that have been newly-defined, involving the various partners in the practical training processes in a more complete and holistic experience.

This article is a product of the formulation of the new model, a unique case study that describes an improvement to the clinical practicum experience. The description of the model's processes relies on experience gained in the successful implementation of the model over the past five years as part of the Academia Class teacher-training program in Israel. The model was applied from 2015 to the present day in dozens of schools throughout the northern district of Israel and was experienced by over 500 student teachers, 500 coach-teachers, 40 pedagogic instructors and academic instructors, lecturers and various other academic role holders led by the Ohalo Academic College.

\subsection{Limitations of the Research}

It is important to note that the research described above is a qualitative-description and interpretative study. In the next stage, we intend to perform a quantitative study to investigate the process described here in greater detail, as well as identify factors contributing to success and operative improvements that may be made to the processes implemented in the field.

\subsection{Operative Recommendations}

Given this experience, we recommend implementation of this model for the teacher-training practicum experience. The model provides advantages over the previous model, enhancing the teacher-training process and offering an overarching umbrella of support, which involves professionals engaged in meaningful reciprocal relations for the benefit of the student teachers.

\section{References}

Allen, J. M., Ambrosetti, A., \& Turner, D. (2013). How school and university supervising staff perceive the pre-service teacher education practicum: A comparative study. Australian Journal of Teacher Education, 38(4). https://doi.org/10.14221/ajte.2013v38n4.9

Appleton, K. (2003). How do beginning primary school teachers cope with science? Toward an understanding of science teaching practice. Research in Science Education, 33(1), 1-25. https://doi.org/10.1023/A:1023666618800

Ariav, T. (2014). Practical experience in teacher-training: Computers a new track. Mofet Institute Journal, 53, 13-19. [Hebrew]

Ariav, T., \& Smith, K. (2006). Creating collaborations between teacher-training institutions and the field: An international view with emphasis on the school model for professional development (PDS). In M. Zilberstein, M. Ben-Porat \& N. Greenfeld (Eds.), A new trend in teacher-training: Partnership between colleges and schools - the Israeli story (pp. 21-67). Tel Aviv: Mofet Institute. [Hebrew]

Arnon, R., \& Presko, B. (2018). Academia Class program from the viewpoint of the trainer-teacher. Research presented at a day seminar entitled: Program research "Academia Class". Tel Aviv: Mofet Institute. [Hebrew]

Bacharach, N. L., Heck, T. W., \& Dahlberg, K. (2010). Changing the face of student teaching through co-teaching. Teacher Development Faculty Publications. Retrieved from https://doi.org/10.1080/01626620.2010.10463538

Boreen, J., Johnson, M., Niday, D., \& Potts, J. (2003). Mentoring beginning teachers. Portland, ME: Stenhouse.

Brandburg, R., \& Ryan, J. (2001). Too little too late: Students' perceptions of changes to practicum placement in teaching. Paper presented at the Australian Association for Research in International Education Research Conference.

Bray, L., \& Nettleton, P. (2006). Assessor or mentor? Role confusion in professional education. Nurse Education Today, 27, 848-855. https://doi.org/10.1016/j.nedt.2006.11.006

Brett, C. (2006). Assisting your preservice teacher to be successful during field experiences. Strategies, 19, 29-32. https://doi.org/10.1080/08924562.2006.10591203

Busher, H., Gündüz, M., Cakmak, M., \& Lawson, T. (2015). Student teachers' views of practicums (teacher-training placements) in Turkish and English contexts: A comparative study. Compare: A Journal of Comparative and International Education, 45(3), 445-466. 
https://doi.org/10.1080/03057925.2014.930659

Carr, J., Herman, N., \& Harris, D. (2005). Creating dynamic schools through mentoring, coaching and collaboration. Alexandra, VA: Association for Supervision and Curriculum Development.

Clark, S., \& Newberry, M. (2019). Are we building preservice teacher self-efficacy? A large-scale study examining teacher education experiences. Asia-Pacific Journal of Teacher Education, 47(1), 32-47. https://doi.org/10.1080/1359866X.2018.1497772

Dvir, N. (2005). Pedagogic instructor: Identities, practices and knowledge in structuring the teaching profession. A Ph.D. dissertation, Herbew University, Jerusalem. [Hebrew]

Emanuel, D. (2005). Perception of the pedagogic instructor's role from three viewpoints. In M. Zilberstein \& R. Reichenberg (Eds.), Restudying the learning program for specialization in pedagogic instruction (Work Paper 2, pp. 69-106). Tel Aviv: Mofet Institute. [Hebrew]

Eran, Z., \& Zaretski, R. (2017). The "Academia Class" program promoting self-efficacy in teaching: A comparative study. Miclol: The Jerusalem College Multidisciplinary Journal, 121-129. [Hebrew]

Eyal, A. (2006). The contradicting logics of teacher-training. In D. Inbar (Ed.), Towards an educational revolution (pp. 166-176)? Jerusalem: Kibbutz Hameuhad and Van Leer Institute. [Hebrew]

Fairbanks, C. M., Freedman, D., \& Kahn, C. (2000). The role of effective mentors in learning to teach. Journal of Teacher Education, 51(2), 102-112. https://doi.org/10.1177/002248710005100204

Feiman-Nemser, S. (2003). What new teachers need to learn. Educational Leadership, 25-30.

Furlong, J. (2011) The English masters in teaching and learning: A new arena for practitioner inquiry? In N. Mockler \& J. Sachs (Eds.), Rethinking educational practice through reflexive inquiry. Dordrech: Springer. https://doi.org/10.1007/978-94-007-0805-1_8

Grossman, P., Hammerness, K., \& McDonald, M. (2009). Redefining teaching, re - imagining teacher education. Teachers and Teaching: Theory and Practice, 15(2), 273-289. https://doi.org/10.1080/13540600902875340

Guise, M., Habib, M., Thiessen, K., \& Robbins, A. (2017). Continuum of co-teaching implementation: Moving from traditional student teaching to co-teaching. Teaching and Teacher Education, 66, 370-382. https://doi.org/10.1016/j.tate.2017.05.002

Hamer-Bodnaro, D. (2014). Pedagogic instruction: The personal and professional-Can they go together? Education and its Surroundings, 36, 161-177. [Hebrew]

Hoy, A. W., \& Spero, R. B. (2005). Changes in teacher efficacy during the early years of teaching: A comparison of four measures. Teaching and Teacher Education, 21(4), 343-356. https://doi.org/10.1016/j.tate.2005.01.007

Jacob, R., Hill, H., \& Corey, D. (2017). The impact of a professional development program on teachers' mathematical knowledge for teaching, instruction, and student achievement. Journal of Research on Educational Effectiveness, 10(2), 379-407. https://doi.org/10.1080/19345747.2016.1273411

Jaspers, W. M., Prins, F., Meijer, P. C., \& Wubbels, T. (2018). Mentor teachers' practical reasoning about intervening during student teachers' lessons. Teaching and Teacher Education, 75, 327-342. https://doi.org/10.1016/j.tate.2018.07.004

Katz, I. (2011). Mentoring as a discourse of love. In A. Yogev \& R. Zuzovski (Eds.), Mentoring from an investigative viewpoint (pp. 48-57). The Kibbutzim College and Mofet Institute. [Hebrew]

Kolb, D. A. (1983). Experiential learning: Experience as the source of learning and development. Prentice-Hall, Englewood Cliffs, New-Jersey.

Kriewaldt, J., \& Turnidge, D. (2013). Conceptualising an approach to clinical reasoning in the education profession. Australian Journal of Teacher Education, 38(6), 7. https://doi.org/10.14221/ajte.2013v38n6.9

Lahav, I. (2010). First and foremost, hands on. On practical experience in teacher-training. Massa, Mofet Institute. [Hebrew] Retrieved from http://portal.macam.ac.il/ArticlePage.aspx?id=2882

Lai, E. (2005). Mentoring for in-service teachers in a distance education programme: Views of mentors, mentees and university teachers. Paper Presented at the Australian Association for Research in Educational Education Research Conference. Parramatta.

Latham, N. I., \& Vogt, W. P. (2007). Do professional development schools reduce teacher attrition? Evidence 
from a longitudinal study of 1,000 graduates. Journal of Teacher Education, 58(2), 153-167. https://doi.org/10.1177/0022487106297840

Le Maistre, C., Boudreau, S., \& Pare, A. (2006). Mentor or evaluator? Assisting and assessing newcomers to the professions. The Journal of Workplace Learning, 18, 344-354. https://doi.org/10.1108/13665620610682071

Loughran, J. (2014). Professionally developing as a teacher educator. Journal of Teacher Education, 65(4), 271-283. https://doi.org/10.1177/0022487114533386

Macdusie, A. (2018). From academia to the classroom: Testing the training model and patterns of assimilation in teaching in three educational sectors. Research presented at a day seminar entitled Research on the Academia Class program. Tel Aviv: Mofet Institute. [Hebrew]

Maskit, D., \& Mevurach, Z. (2013). It can also be done otherwise: Teacher-training according to a collaborative-collegial PDS model. Dafim, 56, 15-34. [Hebrew]

McCormack, C., \& West, D. (2006). Facilitated group mentoring develops key career competencies for university women: A case study. Mentoring and Tutoring, 14, $279-351$. https://doi.org/10.1080/13611260600739290

Milat, S. (1999). What is the difference between "trainer-teacher" and pedagogic instructor? The process of becoming a pedagogic instructor-Case study. Maof veMaase, 5, 1-23. [Hebrew]

Milat, S. (2005). The pedagogic instructor-A central figure in forming the partnership between the college and the school. In M. Zilberstein \& R. Reichenberg (Eds.), Restudying the learning program for specialization in pedagogic instruction (Work Paper 2). Tel Aviv: Mofet Institute. [Hebrew]

Ministry of Education Thinktank. (2014). “Academia Class"-Partnership to reinforce teaching: Concluding policy paper of the thinktank. [Hebrew] Retrieved from http://academia-kita.macam.ac.il/Documents/\%D7\%A2\%D7\%99\%D7\%A7\%D7\%A8\%D7\%99-\%D7\%9E $\%$ D7\%A1\%D7\%9E\%D7\%9A-\%D7\%9E\%D7\%93\%D7\%99\%D7\%A0\%D7\%99\%D7\%95\%D7\%AA-\%D7 \%90\%D7\%97\%D7\%A8\%D7\%99-\%D7\%AA\%D7\%99\%D7\%A7\%D7\%95\%D7\%A0\%D7\%99\%D7\%9D.p df

Murrell Jr, P. C. (2001). The community teacher: A new framework for effective urban teaching. Teachers College Press, Columbia University, 1234 Amsterdam Avenue, New York, NY 10027.

Naifeld, E., \& Nissim, Y. (2019). Co-teaching in the" Academia Class": Evaluation of advantages and frequency of practices. International Education Studies, 12(5), 86-98. https://doi.org/10.5539/ies.v12n5p86

Rajuan, M., Beijaard, D., \& Verloop, N. (2008). Student teachers' perceptions of their mentors as internal triggers for learning. Teaching Education, 19, 279-292. https://doi.org/10.1080/10476210802339951

Ran, A. (2017). The role of the pedagogic instructor in Israel and the world: Selected models from Ireland, Holland, Israel, Singapore and Sweden (L. Yosefsburg Ben-Yehoshua Ed.). Tel Aviv: Mofet Institute. [Hebrew]

Ran, A. (2018). Field grounded teacher-training program: Teacher programs residency. In L. Yosefsburg Ben-Yehoshua (Ed.), Survey of selected models. Tel Aviv: Mofet Institute. [Hebrew]

Ratner, D., \& Shmuel, H. (2017). The Academia Class program: Evaluation research findings in 2016. National Measurement \& Evaluation Authority, Jerusalem: Ministry of Education. [Hebrew]

Ridley, D. S., Hurwitz, S., Hackett, M. R. D., \& Miller, K. K. (2005). Comparing PDS and campus-based preservice teacher preparation. Is PDS-based preparation really better? Journal of Teacher Education, 56, 46-56. https://doi.org/10.1177/0022487104272098

Ronen, A., Daniel-Saad, A., \& Holtzblatt, R. (2018). Trial of the Academia Class model in comparison with the traditional model as evaluated by students from Jewish society and from Arab society. Research report recommended by the Committee for Inter-collegial Research, Mofet Institute. [Hebrew]

Ronfeldt, M., \& Reining, M. (2012). More or better student teaching? Teaching and Teacher Education, 28(8), 1091-1106. https://doi.org/10.1016/j.tate.2012.06.003

Sabar Ben-Yehoshua, N. (2016). Traditions and genres in qualitative research. Tel-Aviv: Mofet Institute. [Hebrew]

Shkedi, A. (2003). Words that are meant to touch: Qualitative research-theory and implementation. Tel Aviv: 
Ramot and University of Tel Aviv. [Hebrew]

Shulman, L. S. (1987). Knowledge and teaching: Foundations of the new reform. Harvard Educational Review, 57, 1-22. https://doi.org/10.17763/haer.57.1.j463w79r56455411

Soslau, E. (2012). Opportunities to develop adaptive teaching expertise during supervisory conference. Teaching and Teacher Education, 28, 768-779. https://doi.org/10.1016/j.tate.2012.02.009

Sundli, L. (2007). Mentoring: A new mantra for education? Teaching and Teacher Education, 23, 201-214. https://doi.org/10.1016/j.tate.2006.04.016

Taylor, E. W., \& Cranton, P. (2012). The handbook of transformative learning: Theory, research, and practice. John Wiley \& Sons.

Wæge, K., \& Haugaløkken, O. K. (2013). Based and hands-on practical teacher education: An attempt to combine the two. Journal of Education for Teaching, 39(2), 235-249. https://doi.org/10.1080/02607476.2013.765195

Walkington, J. (2005). Becoming a teacher: Encouraging development of teacher identity through reflective practice. Asia-Pacific Journal of Teacher Education, 33, 53-64. https://doi.org/10.1080/1359866052000341124

Yogev, A., \& Zuzovski, R. (2011). Mentoring from an investigative viewpoint. The Kibbutzim College and Mofet Institute. [Hebrew]

Zidan, R., \& Aliyan, S. (2013). Satisfaction of practicing teaching according to the PDS model of practical work of students and of other factors involved. Dafim, 56, 259-261. [Hebrew]

Zilberstein, M., Guz, O., \& Pnievski, P. (2005). The instruction triangle: Pedagogic instructor-student-trainer-teacher. Tel Aviv: Mofet Institute. [Hebrew]

Ziv, S., Zilberstein, M., \& Tamir, P. (1992). The gap between pedagogic instructors and trainer-teachers in evaluation of students' teaching. Studies in Education: Journal for Research in Education, 57, 179-192. [Hebrew]

Zuzovsky, R. (1991). Professional development of the teacher and its implementation in teacher-training. Teaching Methods, Journal of Teacher-training and Courses, 59-84. Jerusalem: Ministry of Education and Culture. [Hebrew]

Zuzovsky, R., \& Donitsa-Schmidt, S. (2017). Comparing the effectiveness of two models of initial teacher education programmes in Israel. European Journal of Teacher Education, 40(3), 413-431. https://doi.org/10.1080/02619768.2017.1318377

\section{Copyrights}

Copyright for this article is retained by the author, with first publication rights granted to the journal.

This is an open-access article distributed under the terms and conditions of the Creative Commons Attribution license (http://creativecommons.org/licenses/by/4.0/). 